\title{
Twin delivery- an update: Mini review
}

\begin{abstract}
The use of assisted reproduction has caused an increase in the prevalence of twins. Twin pregnancies are high-risk pregnancies: they are associated with prematurity and its manifestations including sepsis, enterocolitis and respiratory complications. These complications increase the mortality rate of twin delivery in comparison to singleton delivery greatly.
\end{abstract}

Knowledge of the appropriate management of the twin delivery is paramount to avoid life-threatening complications and to decrease the mortality of twins. After going through the literature we present the latest studies on twin delivery.

Keywords: twin delivery, vertex, breech, extraction, trial of labor
Volume 9 Issue 4 - 2018

\author{
Maria Zormpa \\ Department of Obstetrics and Gynecology, Hospital of Muri, \\ Switzerland \\ Correspondence: Maria Zormpa MD, Junior Consultant, \\ Department of Obstetrics and Gynecology, Hospital of Muri, \\ Spitalstrasse 144, 5630 Muri, Switzerland, Tel +4 I-056-675-1577, \\ Email mariazormpa7@gmail.com
}

Received: June 17, 2018| Published: July 12, 2018

\section{Introduction}

Twin deliveries are more common during the last years because of assisted reproduction techniques. ${ }^{1}$ As a twin delivery ishighrisk, especially regarding the delivery of the second twin, extensive intrapartum monitoring and relatively fast operative steps are required to achieve low morbidity. Up to date, the studies support mostly the vaginal delivery in case of both twins in vertex presentation as the method with the best perinatal outcome. ${ }^{2}$

We present an overview of the current literature on the factors influencing the outcome of twin delivery.

\section{Results}

About half of twin deliveries are preterm and possible complications include respiratory distress syndrome, necrotising enterocolitis and sepsis. In addition, growth restriction is another factor increasing perinatal morbidity and mortality. ${ }^{3}$ Concequently, the perinatal mortality is three times greater than the mortality rate of singleton deliveries and it is important to choose the best delivery route. $^{4}$

Lately, there has been a decrease in vaginal deliveries of twins due to increase to elective cesarian sections and combined vaginalcesarean deliveries. Risk factors of vaginal-cesarean delivery are a non-vertex second twin and a prolonged interval between the delivery of twins. ${ }^{5}$

Malpresentation of the second twin can lead to complications. In case of vertex- presentation of both twins, the delivery is relatively safe. Different studies support a cesarean section as a route of delivery in case of non-vertex presentation of the second twin and if the estimated weight is less than 2000 grams. ${ }^{2}$ However, breech extraction or internal cephalic version can be attempted. External cephalic version can be used to rotate twin $\mathrm{B}$, especially in conjuction with tocolytics, epidural anesthesia, even in multiple attempts. ${ }^{6}$

According to some, when twin B presents in vertex or breech or weight discrepancy is less than $25 \%$ between the twins, the risk of requiring a cesarean is low. Apart from that, epidural anesthesia acts as a protective factor that can increase the rates of vaginal delivery in twin pregnancies. ${ }^{7}$

Additionally, studies suggest that in twin deliveries of twin A/ and or twin B in non-cephalic presentation a cesarian section has no impact on the perinatal outcome. ${ }^{8}$
The Twin Birth Study supports that a planned cesarean section has no benefit for the child. As a result, in case of vertex presentation of twin A, vaginal delivery should be favored, as long as guidelines of twin delivery are respected. Continuous monitoring is necessary during the delivery. In addition, twin-to-twin delivery time interval increases the risk of reduction in $\mathrm{pH}$, base excess and fetal acidosis, as well as Apgar less than 5 after 1, 5 and 10 minutes. ${ }^{9}$ Ultrasound monitoring is crucial to monitor the fetal heart rate and to control the presentation of twin $\mathrm{B}$.

Concerning preterm pregnancies, the late preterm twins benefit from a vaginal delivery in case of twin $\mathrm{A}$ in vertex presentation and twin $\mathrm{B}$ in vertex/non-vertex presentation. ${ }^{10}$ However, data regarding twins with a weight of less than $1500 \mathrm{~g}$ are inconclusive as far as the route of delivery is concerned (Figure 1). ${ }^{11}$

A trial of labor after cesarean section (TOLAC) has been evaluated for women with twin pregnancies. The rate of vaginal birth after secarean section (VBAC) reached $64.5 \%$ and combined delivery $45 \% .^{12}$ Women who chose TOLAC had the same success rates of VBAC as women with singleton pregnancies. There was no statistical difference in intrapartum death, neonatal death, cord blood $\mathrm{pH}$, uterine rupture. ${ }^{13}$

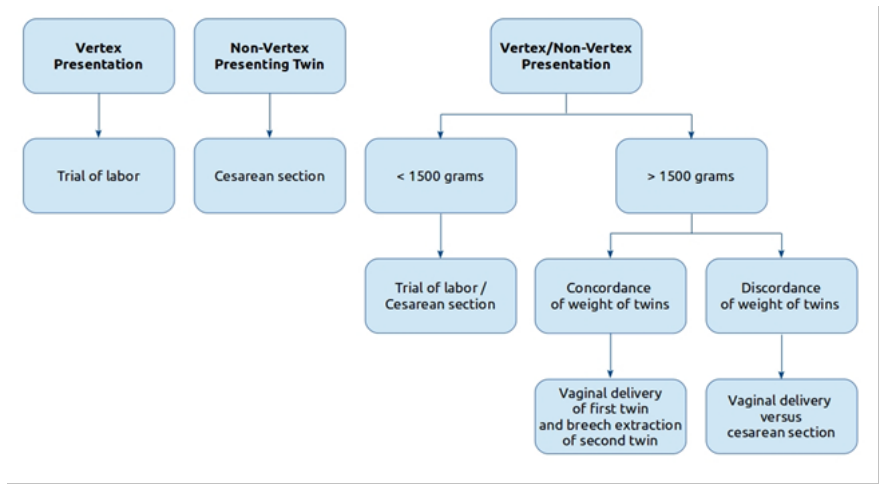

Figure I Flow chart showing the route of delivery of twin deliveries.

\section{Discussion}

Studies evaluating the delivery of twin gestation support that when both twins are in vertex presentation a trial of labor should be anticipated. In case of non-vertex presenting twin the mode of delivery should be cesarean section. 
However, the literature is inconclusive with regards to the best route of delivery when twin B is non-vertex. For term twins or late preterm vaginal delivery should be attempted. For babies lighter than $1500 \mathrm{~g}$ more studies should be conducted in order to evaluate the best route of delivery. With twin delivery becoming more commonplace, skills of obstetricians for the delivery of the non-vertex twin B, mostly in breech extraction are essential to avoid serious complications.

\section{Acknowledgments}

None.

\section{Conflict of interest}

The authors declare that they have no conflict of interest.

\section{References}

1. Barrett JF. Twin delivery: method, time, conduct. Best Pract Res Clin Obstet Gynaecol. 2014;28(2):327-38.

2. Boqqess KA, Chisholm CA. Delivery of the nonvertex second twin. A review of the literature. Obstet Gynecol Surv. 1997;52(12):728-35.

3. Christopher D, Robinson BK, Peaceman AM. An evidence-based approach to determining route of delivery for twin gestations. Rev Obstet Gynecol. 2011;4(3-4):109-16.

4. Barrett JF, Ritchie WK. Twin delivery. Best Pract Res Clin Obstet Gynecol. 2002;16(1):43-56.

5. Persad VL, Baskett TF, O Connell CM, et al. Combined vaginal-cearean delivery of twin pregnancies. Obstet Gynecol. 2001;98(6):1032-7.
6. Hutton EK, Hannah ME, Barrett J. Use of external cephalic version for breech pregnancy and mode of delivery for breech and twin pregnancy: a survey of Canadian practicioners. J Obstet Gynaecol Can. 2002;24(10):804-10.

7. Williams KP, Galerneau F. Intrapartum influences on cesarean delivery in multiple gestation. Acta Obstet Gynecol Scand. 2003;82(3):241-5.

8. Steins Bisschop CN, Vogelvang TE, May AM, et al. Mode of delivery in non-cephalic presenting twins: a systematic review. Arch Gynecol Obstet. 2012;286(1):237-47.

9. Fox NS, Silverstein M, Bender S, et al. Active second-stage management in twin pregnancies undergoing planned vaginal delivery in a U.S. population. Obstet Gynecol. 2010;115(2 Pt 1):229-33.

10. Hogle KL, Hutton EK, McBrien KA, et al. Cesarean delivery for twins: a systematic review and meta-analysis. Am J Obstet Gynecol. 2003;188(1):220-7.

11. Zhang J, Bowes WA, Grey TW, et al. Twin delivery and neonatal and infant mortality: a population-based study. Obstet Gynecol. 1996;88(4 Pt 1):593-8.

12. Varner MW, Leindecker S, Spong CY, et al. The Maternal-Fetal Unit cesarean registry. Am J Obstet Gynecol. 2005;193(1):135-40.

13. Cahill A, Stamilio DM, Paré E, et al. Vaginal birth after cesarean section (VBAC) attempt in twin pregnancies: is it safe ? Am J Obstet Gynecol. 2005;193(3 Pt 2):1050-5. 